\title{
Biocombustíveis: uma análise da evolução do biodiesel no Brasil
}

\author{
Cíntia Letícia Sallet ${ }^{*}$
}

Augusto Mussi Alvim**

\begin{abstract}
RESUMO - O objetivo do presente artigo é analisar a evolução dos biocombustíveis no Brasil, com foco no biodiesel. São apresentados e discutidos os programas e metas estabelecidos pelo Governo, a legislação existente, as matérias-primas utilizadas, a sua importância na matriz energética nacional, a sua produção, formação de preço e leilões, além de questões relevantes para a análise dos resultados obtidos a partir do lançamento do marco regulatório. As conclusões observadas são de que o Programa Nacional de Produção e Uso de Biodiesel pode ser considerado um sucesso do ponto de vista de crescimento do mercado, com a antecipação de metas de mistura, tendo a soja como principal matéria-prima. Porém, muitas questões ainda precisam evoluir, como o desenvolvimento de novas matérias-primas, de preferência não alimentícias, redução dos preços, aumento de produtividade e maior inserção social em comunidades pobres.
\end{abstract}

Palavras-chave: Biocombustíveis. Biodiesel. Matriz energética.

\section{INTRODUÇÃO}

Tendo em vista o aumento do consumo dos derivados de petróleo, a provável redução das suas reservas e a fragilidade nas relações internacionais envolvendo os principais países produtores, existe uma preocupação crescente tanto com o aumento e a volatilidade dos preços, como quanto às consequências do seu uso sobre as mudanças climáticas do planeta provocadas pelo efeito estufa.

O principal acordo sobre mudanças climáticas é o Protocolo de Kyoto (1997), o qual estabelece metas para a redução de emissões de dióxido de carbono $\left(\mathrm{CO}_{2}\right.$ - resultante da queima de combustíveis fósseis) na atmosfera. $\mathrm{O} \mathrm{CO}_{2}$ é um dos principais gases de efeito estufa (GEE) e uma das maneiras de reduzir sua emissão é mudar a matriz de produção energética, utilizando fontes de energia renováveis, mais eficientes e menos poluentes.

Uma alternativa energética é a utilização de biocombustíveis, tanto do ponto de vista ambiental, como econômico e social. A conjugação de fatores, como o aumento dos preços do petróleo, a poluição ambiental e as alterações climáticas, estão impulsionando o uso de biocombustíveis como uma alternativa de energia renovável e menos poluente capaz de fomentar

\footnotetext{
*Mestre em Economia do Desenvolvimento. Endereço eletrônico: cintia@ecoplan.com.br.

${ }^{* *}$ Doutor em Economia pela Universidade Federal do Rio Grande do Sul. É professor do Departamento de Economia e do Programa de Pós-Graduação em Economia da Pontifícia Universidade Católica do Rio Grande do Sul. Endereço eletrônico: augusto.alvim@pucrs.br.
} 
o desenvolvimento de regiões agrícolas pobres.

Ao longo dessas três décadas, o Brasil conseguiu desenvolver a produção e a indústria do álcool de maneira competitiva no mercado mundial; prova disso são os números expressivos da produção e consumo dentro do país e também na exportação do combustível, que no ano de 2009 foi de 3,3 milhões de metros cúbicos, tendo como principais destinos a região ÁsiaPacífico (31,1\%) e o continente europeu (28,2\%) (ANP, 2010).

Já a produção de biodiesel no Brasil tem uma história mais recente e passa por um momento importante de definições e superação de desafios. Se comparadas a produção de etanol e biodiesel no país, percebe-se que o etanol possui uma tecnologia consolidada em relação à do biodiesel, que é incipiente.

Dessa maneira, a proposta deste estudo é analisar como está estruturada a produção de biodiesel hoje no Brasil, após a criação do Programa Nacional de Produção e Uso de Biodiesel (PNPB). De forma conjunta, buscou-se identificar as perspectivas futuras e os principais desafios para garantir um crescimento sustentável do setor.

\section{BIODIESEL}

Knothe et al. (2006) definiram biodiesel como produto derivado a partir de muitas matérias-primas distintas, entre elas, óleos vegetais, gorduras animais, óleos usados em frituras e matérias graxas de alta acidez. Fatores como a geografia, o clima e a economia determinam quais matérias-primas apresentam maior interesse e melhor potencial para emprego como biodiesel. Nos Estados Unidos o óleo de soja é a principal matéria-prima, na Europa é o óleo de colza (canola) e o óleo de palma é muito utilizado em países tropicais.

\subsection{MATRIZ ENERGÉTICA NACIONAL}

O uso de energias limpas é bem significativo no Brasil, conforme pode ser observado no Gráfico 1, que ilustra a Oferta Interna de Energia no Brasil (OIE) ${ }^{1}$. Essa figura revela o quão diversificado é o Brasil quanto à disponibilidade de energia limpa ou renovável. A maior parte $(45,4 \%)$ da energia gerada no Brasil provém da soma dos recursos renováveis de biomassa $(31,3 \%)$ e das usinas hidroelétricas $(14,1 \%)$. Os recursos de biomassa são compostos por produtos da cana-de-açúcar $(17,4 \%)$, lenha e carvão vegetal $(10 \%)$ e outras fontes renováveis (3,9\%). A segunda maior fonte de energia (37,5\%), petróleo e seus derivados, é de origem fóssil. Gás natural $(10,3 \%)$, carvão mineral $(5,3 \%)$ e urânio $(1,4 \%)$ representam a menor parte da 1 A Oferta Interna de Energia (OIE) é a soma do consumo final de energia, das perdas na distribuição e armazenagem e das perdas nos processos de transformação, ou seja, é a demanda total de energia, também chamada de Matriz Energética. 
geração nacional de energia.

GRÁFICO 1 - OFERTA INTERNA DE ENERGIA NO BRASIL - 2010

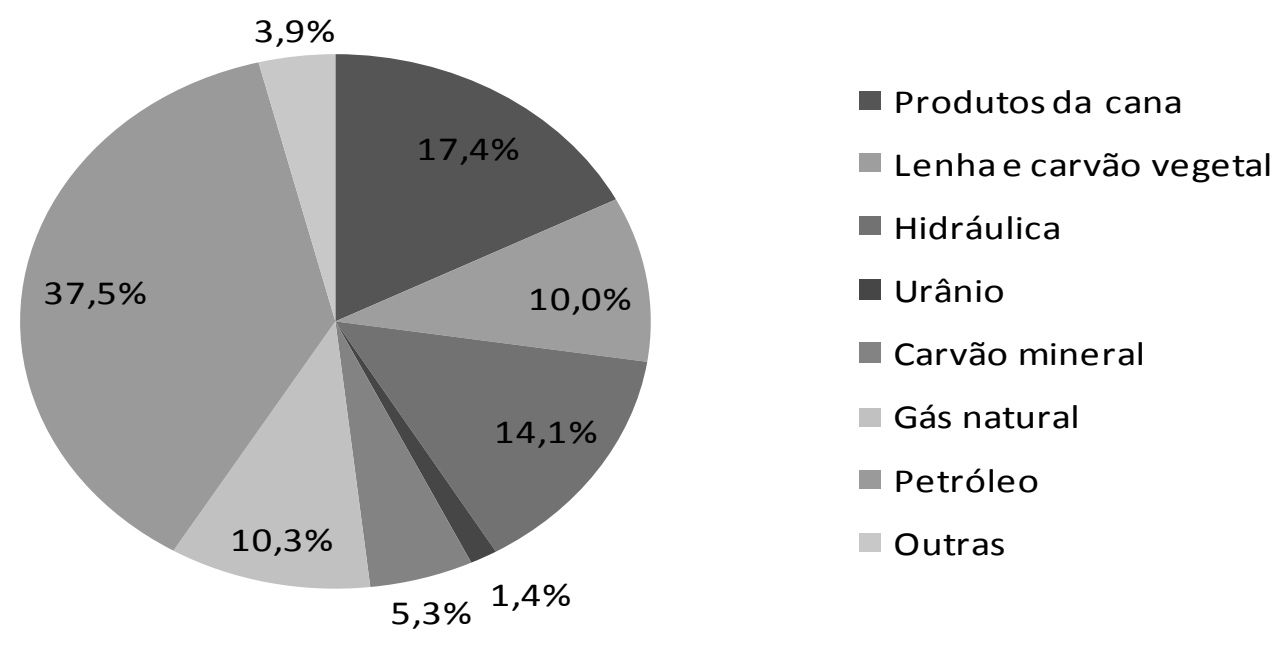

FONTE: Ministério de Minas e Energia - Boletim Mensal de Energia, dezembro de 2010.

Segundo dados do Ministério de Minas e Energia para o ano de 2009, o Brasil já possuía vantagens na produção de energias renováveis, com mais de $40 \%$ da matriz energética brasileira, contra apenas 7,2\% nos países da $\mathrm{OECD}^{2}$ e de $12,7 \%$ na média mundial. A expressiva participação da energia hidráulica e o uso representativo de biomassa proporcionam essa vantagem.

O uso de biocombustíveis tem aumentado no Brasil ao longo dos últimos anos e sua participação na matriz energética nacional deverá ser ainda maior de acordo com projeções do Ministério de Minas e Energia.

O etanol e o biodiesel são os principais tipos de biocombustíveis produzidos e utilizados no setor de transportes brasileiro. De 2007 para 2008, a participação da bioenergia (etanol e biodiesel) na matriz energética de transportes brasileira passou de 15\% para 18\% e, segundo o Boletim Mensal dos Combustíveis Renováveis, do Ministério de Minas e Energia (maio de 2010), já é de 20,5\% (Tabela 1).

Como pode ser observado na Tabela 1, destaca-se o consumo de energias renováveis no setor de transportes brasileiro, com o etanol com $18,8 \%$ e o biodiesel com $1,7 \%$. Isto torna o Brasil um dos países com maior presença de fontes renováveis de energia na matriz de transportes, quando comparado aos países da OECD, com apenas 1,9\%, e demais países, com $0,2 \%$.

2 Organisation for Economic Co-operation and Development, formada por 30 países: Alemanha, Austrália, Áustria, Bélgica, Canadá, Coreia do Sul, Dinamarca, Espanha, Estados Unidos, Finlândia, França, Grécia, Holanda, Hungria, Irlanda, Islândia, Itália, Japão, Luxemburgo, México, Noruega, Nova Zelândia, Polônia, Portugal, Reino Unido, República Eslovaca, República Tcheca, Suíça, Suécia e Turquia. 
TABELA 1 - MATRIZ ENERGÉTICA DO SETOR DE TRANSPORTES

\begin{tabular}{lrrr}
\multicolumn{1}{c}{ Total Transporte } & mil tep $^{\mathbf{3}}$ & $\mathbf{\%}$ & \\
\hline Diesel fóssil & 29.297 & 46,7 \\
Biodiesel & 1.072 & 1,7 \\
Gasolina & 14.720 & 23,5 \\
Etanol & 11.792 & 18,8 \\
Querosene & 2.828 & 4,5 \\
Gás Natural & 1.853 & 3,0 \\
Eletricidade & 137 & 0,2 \\
Outros & 986 & 1,6 \\
Total & 62.685 & 100 \\
\hline
\end{tabular}

FONTE: Ministério de Minas e Energia - Boletim Mensal dos Combustíveis Renováveis, maio de 2010.

\subsection{MATÉRIAS-PRIMAS UTILIZADAS}

Segundo Ramos et al. (2003), entre várias fontes disponíveis para a geração de energias renováveis, os óleos vegetais se destacam não só pela adequação das suas propriedades, mas também por representarem forte apoio à agricultura familiar, criando melhores condições de vida (infraestrutura) em regiões carentes, valorizando potencialidades regionais e oferecendo alternativas a problemas econômicos e socioambientais de difícil solução.

Segundo Câmara (2006), existem muitas matérias-primas de uso potencial para produção de biodiesel no Brasil, que podem ser divididas por classes de fontes renováveis:

a) Óleos vegetais: líquidos à temperatura ambiente, como os óleos de soja, algodão, amendoim, babaçu, canola, dendê, girassol, mamona;

b) Gorduras animais: pastosas ou sólidas à temperatura ambiente, como o sebo bovino, óleo de peixe, banha de porco, óleo de mocotó;

c) Óleos e gorduras residuais: matérias-primas relacionadas ao meio urbano, como óleos residuais originários de cozinhas domésticas e industriais (óleo de fritura); gordura sobrenadante (escuma) de esgoto; óleos residuais de processamentos industriais.

Devido a sua vasta extensão territorial, o Brasil apresenta uma grande diversidade de matérias-primas de origem vegetal para a produção de biodiesel. Porém, a viabilidade de cada matéria-prima dependerá de suas propriedades técnicas, sua competitividade econômica e seus benefícios socioambientais, contemplando aspectos como: teor de óleo; produtividade agrícola

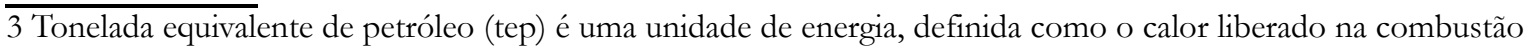
de uma tonelada de petróleo cru. 
(produção por unidade de área); equilíbrio agronômico; diferentes sistemas de produção; ciclo cultural (sazonalidade); adaptação regional; e impacto socioambiental de seu desenvolvimento. A análise desses aspectos é de extrema importância para definir estratégias de produção e exploração do potencial energético dos recursos naturais disponíveis de forma sustentável e eficiente (RAMOS, 1999, 2003).

Como podemos observar na Tabela 2, cada região do país possui diversas opções de matérias-primas para produção de biodiesel.

TABELA 2 - PLANTAS OLEAGINOSAS DISPONÍVEIS PARA PRODUÇÃO DE BIODIESEL NO BRASIL

\begin{tabular}{lrr}
\hline \multicolumn{1}{c|}{ Região } & Óleos vegetais disponíveis \\
\hline $\begin{array}{l}\text { Norte } \\
\text { Nordeste }\end{array}$ & Babaçu, soja, mamona, dendê, algodão e coco \\
$\begin{array}{l}\text { Centro-oeste } \\
\text { Sudeste }\end{array}$ & Soja, mamona, algodão, girassol, dendê e gordura animal \\
Sul & Soja, mamona, algodão e girassol \\
\hline
\end{tabular}

FONTE: PARENTE (2003).

Quanto aos estudos desenvolvidos para utilização na produção nacional de biodiesel, as espécies de plantas oleaginosas mais pesquisadas são: a soja, o girassol, a mamona, o milho, o pinhão-manso, o caroço de algodão, a canola, o babaçu, o buriti, o dendê e o amendoim (PARENTE, 2003; RAMOS et al., 2003).

Segundo dados da Associação Brasileira das Indústrias de Óleos Vegetais (ABIOVE), de novembro de 2010, o Brasil já é o terceiro maior produtor mundial de biodiesel, produzindo 2,2 milhões de toneladas, perdendo apenas para a Alemanha (2,5 milhões) e para a França (2,3 milhões de toneladas). Também de acordo com a ABIOVE, a soja é a principal cultura agrícola do Brasil, em volume de produção e geração de renda.

Segundo a ANP (informações referentes ao mês de setembro 2010), a principal matéria-prima utilizada para a produção de biodiesel no Brasil é o óleo de soja, que contribui com 81,36\% da produção; em segundo lugar está a gordura bovina com 13,36\%, em terceiro o óleo de algodão com 4,11\% e o restante é composto por outros materiais graxos (0,56\%): óleo de fritura usado $(0,19 \%)$, gordura de porco $(0,18 \%)$, óleo de palma $(0,10 \%)$, gordura de frango $(0,09 \%)$ e óleo de girassol (0,05\%) (Gráfico 2).

O óleo de soja surgiu como um subproduto do processamento do farelo de soja e, atualmente, tornou-se um dos líderes mundiais no mercado de óleos vegetais. Pela importância que o agronegócio da soja representa para o mercado brasileiro, é relativamente fácil identificar que essa oleaginosa detém o maior potencial para servir como paradigma no desenvolvimento de um programa nacional de biodiesel. 
GRÁFICO 2 - PRINCIPAIS MATÉRIAS-PRIMAS EMPREGADAS NA PRODUÇÃO DE BIODIESEL NO BRASIL

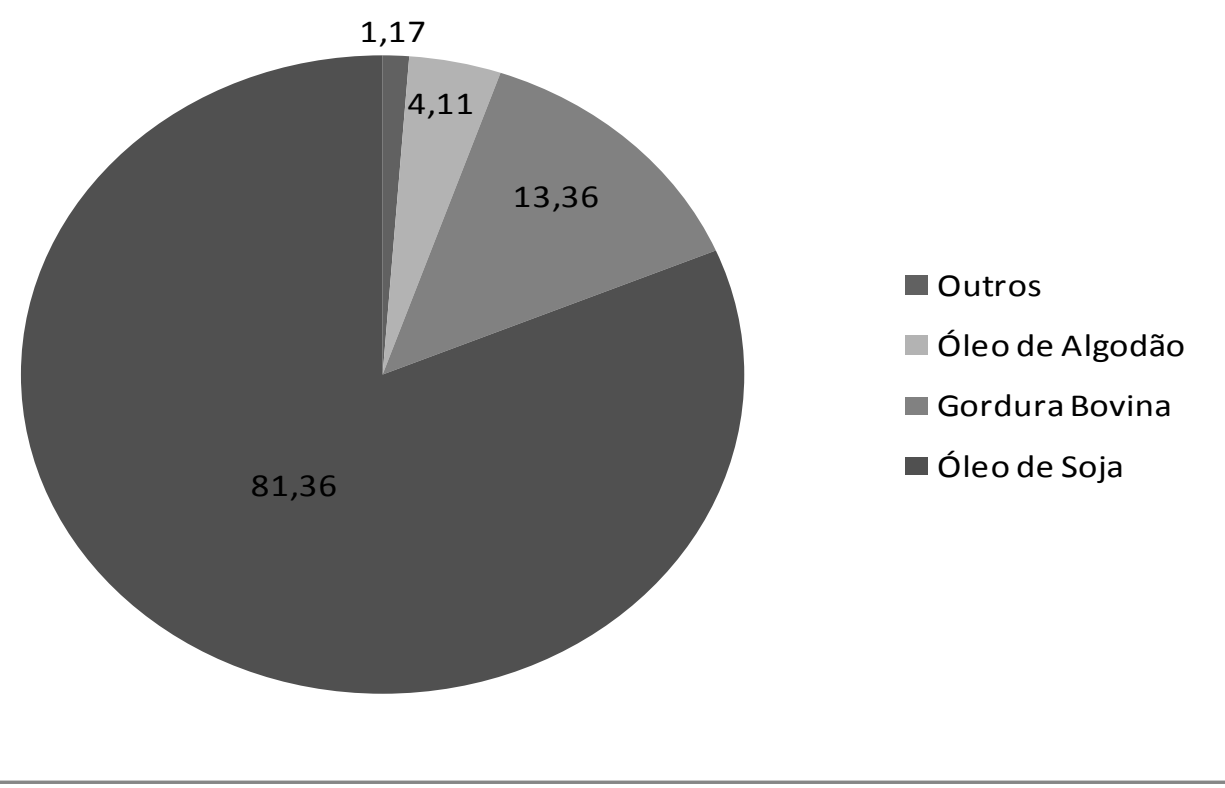

FONTE: ANP - Boletim Mensal de Biodiesel, outubro de 2010.

Várias outras oleaginosas, em fase de avaliação e desenvolvimento de suas cadeias produtivas, podem ser empregadas para a produção de biodiesel. Muitas já tiveram suas propriedades técnicas, sua competitividade econômica e seus benefícios socioambientais atestados, restando a implementação de projetos de ampliação de escala e a condução de estudos agronômicos mais aprofundados que venham a garantir sua disponibilidade nos momentos de maior demanda (HEIFFIG; CÂMARA, 2006).

Portanto, a cultura da soja tem sido, até o momento, o sustentáculo de boa parte da produção nacional de biodiesel, justamente pelo fato desse importante agronegócio apresentar a escala necessária para atender as metas definidas no PNPB com preços competitivos.

\section{A LEGISLAÇÃO E O PROGRAMA NACIONAL DE PRODUÇÃO E USO DE BIO- DIESEL}

Motivado pela a crise mundial do petróleo na década de 70, o governo brasileiro desenvolveu o Programa Nacional do Álcool Combustível - Pró-Álcool, utilizando a cana-deaçúcar como matéria-prima para produção de álcool combustível, com o objetivo de reduzir a dependência externa por petróleo e desenvolver o setor sucroalcooleiro do país. Atualmente, o setor apresenta-se desenvolvido e bem sucedido.

Concomitantemente ao Pró-Álcool, cogitou-se o desenvolvimento de um programa para produção de outro combustível de origem renovável, porém a base de matérias-primas 
oleaginosas, com o intuito de substituir parcialmente o diesel derivado do petróleo. $\mathrm{Na}$ época, o programa foi chamado de "Pró-Óleo" ou "Pró-Diesel" (CÂMARA, 2006).

Foram desenvolvidas pesquisas sobre o biodiesel, e o Brasil foi um dos pioneiros ao registrar a primeira patente sobre o processo de produção em 1980 (PNPB, PORTAL DO PROGRAMA NACIONAL DE PRODUÇÃO E USO DE BIODIESEL). Entretanto, o programa permaneceu por muitos anos apenas como uma ideia para o futuro. Com o atual cenário de crise energética mundial, a ideia foi retomada, através do lançamento pelo Governo Federal do Programa Nacional de Produção e Uso de Biodiesel (PNPB).

O Programa Nacional de Produção e Uso de Biodiesel é um programa interministerial do Governo Federal que objetiva a implementação de forma sustentável, tanto técnica, como economicamente, da produção e uso do biodiesel no Brasil, com enfoque na inclusão social e no desenvolvimento regional, através da geração de emprego e renda.

Através do PNPB, o Governo organizou a cadeia produtiva, definiu as linhas de financiamento, estruturou a base tecnológica e, em termos do marco regulatório do novo combustível, definiu como prioridade a ampliação da produção e consumo em escala comercial e de forma sustentável, com enfoque na inclusão social e no desenvolvimento regional, através da diversificação das matérias-primas e das regiões produtoras, visando gerar emprego e renda (PNPB, PORTAL DO PROGRAMA NACIONAL DE PRODUÇÃO E USO DE BIODIESEL).

As principais diretrizes do PNPB são:

a) Implantar um programa sustentável, promovendo inclusão social;

b) Garantir preços competitivos, qualidade e suprimento;

c) Produzir biodiesel a partir de diferentes fontes oleaginosas e em regiões diversas.

Desde sua criação, o PNPB foi concebido trazendo como principais diretrizes a promoção da inclusão social e a redução das disparidades regionais. Com o objetivo de garantir espaço para a agricultura familiar, e assegurar a promoção da inclusão social, o Ministério do Desenvolvimento Agrário (MDA) estabeleceu os critérios e procedimentos relativos à obtenção, manutenção, renovação, suspensão e cancelamento da concessão e uso de uma certificação, o "Selo Combustível Social".

Criado através da Instrução Normativa no 1, de 5 de julho de 2007, o Selo Combus- 
tível Social diferencia as empresas de produção de biodiesel que apoiam a agricultura familiar: entre os critérios para obtenção e manutenção do Selo, está a obrigatoriedade de compra de percentuais mínimos de matérias-primas de agricultores familiares enquadrados nos critérios do PRONAF (Programa Nacional de Fortalecimento da Agricultura Familiar).

O Selo é concedido aos produtores que comprarem matéria-prima da agricultura familiar em percentual mínimo de 15\%, para as aquisições provenientes das regiões norte e centro-oeste, e 30\% para as aquisições provenientes das regiões sul, sudeste e nordeste. As indústrias com o Selo têm as alíquotas de PIS/PASEP e COFINS reduzidas e acesso a melhores condições de financiamento público junto ao BNDES e instituições financeiras credenciadas (Banco da Amazônia, Banco do Nordeste do Brasil e Banco do Brasil), além de permissão para usar o Selo com fins de promoção comercial de sua empresa.

Outra exigência é que sejam feitos contratos entre as indústrias e os agricultores familiares, estipulando prazos, valores de compra, critérios de reajuste de preços e condições de entrega da matéria-prima. Os contratos devem ser negociados com pelo menos um representante dos agricultores familiares (entidades sindicais ou outras instituições credenciadas pelo MDA) e as indústrias devem assegurar assistência e capacitação técnica aos agricultores familiares.

Ao contrário do Pro-Álcool, o PNPB, desde a sua formulação inicial, tem a preocupação central de aliar a renovação da matriz energética à inclusão social e à redução das disparidades regionais.

Segundo Abramovay e Magalhães (2007), é a primeira vez que o Governo cria condições para que uma parte da oferta de matéria-prima de uma determinada indústria seja proveniente de unidades produtivas que, sem esta intervenção, dificilmente teriam participação no mercado, pois seria muito complicado para a agricultura familiar ter acesso à cadeia produtiva do biodiesel em condições normais de competição, especialmente nas regiões norte e nordeste do país; e a exigência da formalização e da negociação de contratos entre as indústrias e os agricultores familiares (representados pelas organizações sindicais), com a mediação do MDA, representa uma importante inovação, uma nova forma de inserção dos agricultores familiares na cadeia produtiva.

De maneira geral, o Selo Social tenta evitar que o mercado de biodiesel seja dominado por apenas um produto (por exemplo, a soja) e, consequentemente, pelas regiões que tradicionalmente são grandes produtoras; sendo assim, além de oferecer aos agricultores familiares novas oportunidades de acesso a mercados, a legislação do PNPB prioriza as regiões mais carentes do país, que concentram os segmentos mais pobres da agricultura familiar brasileira, especialmente aqueles que habitam no semiárido (CARVALHO; POTENGY; KATO, 2007). 


\section{LEILÕES E FORMAÇÃO DO PREÇO}

A ANP realiza, desde 2005, os leilões de biodiesel, onde refinarias compram o biodiesel para misturá-lo ao diesel derivado do petróleo. O objetivo inicial dos leilões foi gerar mercado e, desse modo, estimular a produção de biodiesel em quantidade suficiente para que refinarias e distribuidores pudessem compor a mistura (BX) determinada por lei.

Os leilões continuam sendo realizados para assegurar que todo o óleo diesel comercializado no país contenha o percentual de biodiesel determinado em lei.

No sistema de leilões e releilões, o produtor de biodiesel vende para a Petrobras (leilão), que vende para os distribuidores (releilão) que depois diluem o biodiesel em B5 e levam até os postos de combustível. O principal ponto positivo deste sistema está na padronização, garantia de qualidade e fiscalização das misturas.

Pode ser uma ameaça para alguns produtores já instalados se o Governo permitir a negociação direta entre produtores e distribuidoras, como acontece com o etanol. Os produtores distantes dos centros consumidores estariam estrategicamente mal posicionados, caso o sistema de leilões fosse abandonado.

A metodologia de formação do preço do biodiesel por parte do Governo é cercada de cuidados para propiciar que as usinas competidoras não consigam pré-determinar o limite imposto no leilão. Dessa forma, o Governo obriga todos os competidores a melhorar suas condições competitivas. Por outro lado, as usinas não apresentam o custo real do biodiesel e, por conseguinte, sua margem de lucro, o que permite que reduções nos custos de produção nas usinas melhore sua competitividade. Essa incerteza faz com que o leilão seja menos previsível, e quem sai ganhando é o consumidor, já que receberá o combustível por um preço mais baixo.

Alguns aspectos da formação dos preços por parte do Governo podem ser discutidos, como a importância da soja e do álcool e os custos relativos ao processo de produção. O resultado dessa interação será um preço de referência, que é a estratégia de controle do Governo para manter limites ao preço máximo aceitável para o consumidor.

O custo da matéria-prima sempre será o principal componente da formulação do preço do biodiesel, pois, na maior parte dos casos, o óleo ou a gordura utilizados respondem por um percentual de 80 a 85\% do preço final do combustível (MENDES; COSTA, 2010).

Como matéria-prima, a soja tem importância muito grande na constituição dos preços, já que 81,36\% do biodiesel produzido tem origem nessa oleaginosa (ANP, BOLETIM MENSAL DE BIODIESEL (2010)). Esse predomínio, aliado ao fato de se constituir em um produto extremamente relevante no mercado brasileiro, torna a soja a matéria-prima de referência, tanto pelo valor em grão, como pelo preço do óleo, como pode ser observado no Gráfico 
3. Cabe ainda o destaque de que a soja, pela sua importância no cenário mundial, influencia os preços dos outros óleos.

\section{GRÁFICO 3 - PREÇO DO LEILÃO X PREÇO DO ÓLEO DE SOJA}

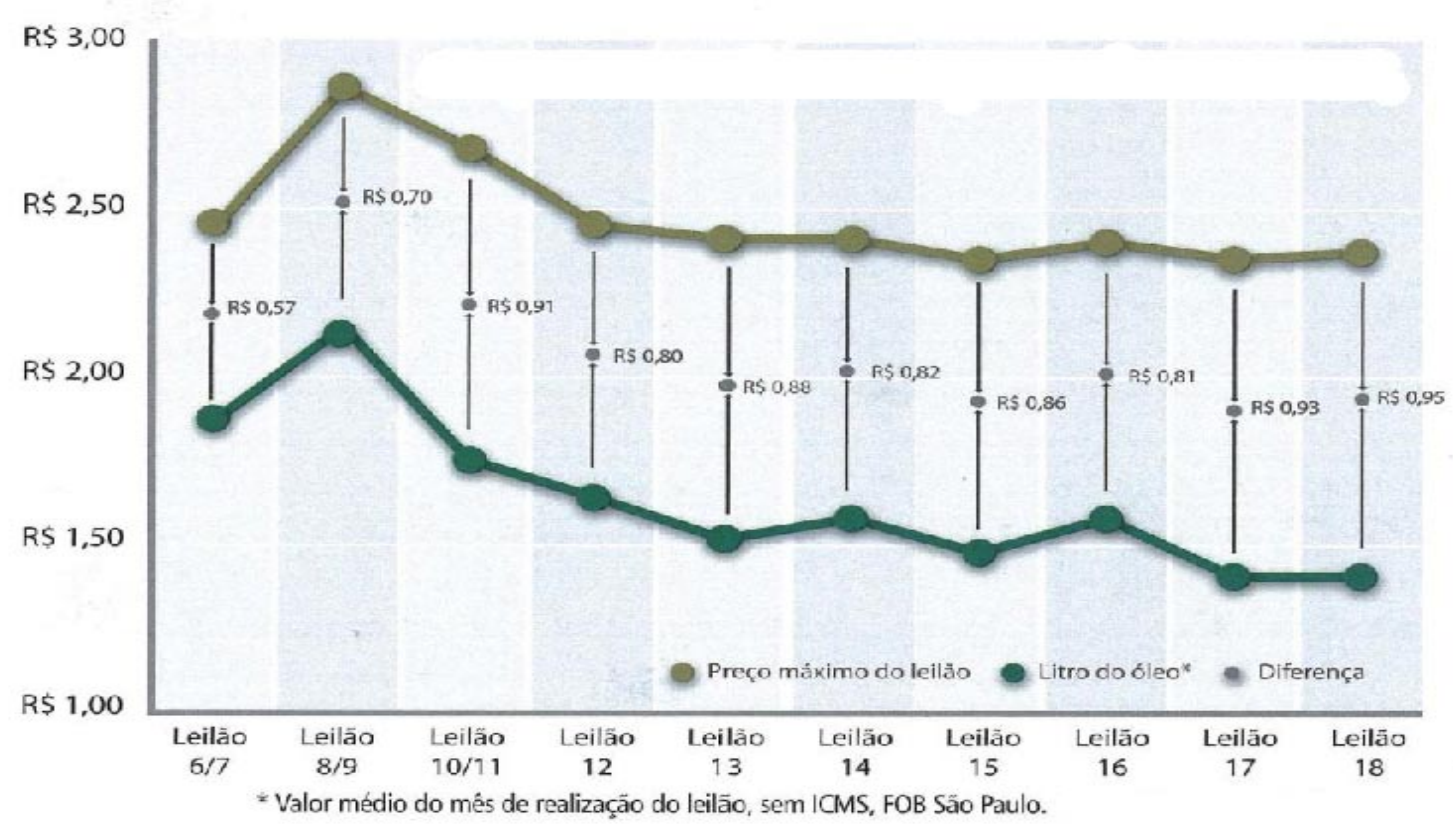

FONTE: Revista Biodieselbr (ago./set. 2010).

A soja tem maior valor do que a maioria dos outros produtos que competem na produção de biodiesel. Também esse fato é conveniente, pois favorece aqueles produtores que utilizam outras matérias-primas, mesmo que em pequenas proporções.

Como se afirmou anteriormente, cerca de $80 \%$ do preço do biodiesel serve para pagar a matéria-prima, e os outros $20 \%$ correspondem ao custo do processo, incluindo aí desde os insumos até o salário dos funcionários.

Dentre os custos que compõem o processo de produção do biodiesel, o álcool aparece como o segundo fator mais importante (depois da soja). Usa-se predominantemente o metanol (rota metílica), e sua contribuição ao custo total do combustível é da ordem de 10\% (MENDES; COSTA, 2010).

Restam cerca de 10\% do custo total do biodiesel para serem analisados. Podem ser citados os insumos (produtos químicos), utilidades (energia, água, vapor), manutenção da planta industrial e os salários e encargos dos trabalhadores envolvidos.

Cabe finalizar este tópico identificando o papel do preço de referência pré-determinado pelo Governo para a realização dos leilões. Trata-se de um valor máximo a ser pago pelo biodiesel naquele evento e, como já foi dito, serve para garantir que o preço se mantenha dentro 
de níveis aceitáveis. O preço final depende da competitividade das usinas e da relação demanda /oferta, que resulta numa aplicação do clássico conceito regulador de mercado. Exemplo disso são leilões em que a oferta era bastante próxima dos valores de demanda e o deságio foi pequeno. A precisão na determinação do preço de referência (ou valor máximo) é fator relevante na inibição de concorrência desleal ou de preços “combinados”, além de incentivar os produtores a encontrar soluções para uma maior competitividade.

\section{CONCLUSÃO}

A contínua elevação do percentual de adição de biodiesel ao diesel e a antecipação da meta de mistura, demonstram o sucesso do Programa Nacional de Produção e Uso de Biodiesel e da experiência acumulada pelo Brasil na produção e no uso em larga escala de biocombustíveis.

A disponibilidade de terra para cultivo de plantas ricas em óleo, o clima favorável, a fertilidade do solo e a experiência acumulada com o Pró-Álcool, dão sustentabilidade à estratégia adotada pelo Governo Federal.

O óleo de soja tornou-se a principal matéria-prima utilizada para a produção de biodiesel, viabilizando as metas propostas, por possuir um setor consolidado, competitivo e com produção em escala. Mas o preço elevado, a baixa produtividade do óleo, a influência sobre o preço dos alimentos e a dificuldade em cumprir os objetivos de inclusão social propostos pelo PNPB, são questões importantes a serem consideradas preliminarmente à adoção de novos marcos regulatórios.

O biodiesel é mais caro do que o diesel (atualmente, a obrigatoriedade da mistura é o que sustenta o setor); se o biodiesel fosse mais competitivo não haveria essa necessidade, e sendo mais competitivo deixaria de ser um complemento ao diesel, passando a exercer um papel mais importante na matriz energética.

Uma questão que emerge neste cenário de regulação econômica subordinada a um marco legal é como garantir a intenção expressa das políticas públicas de promover a sustentabilidade econômica e social em comunidades pobres.

A produção de biodiesel, da maneira como está estruturada, tendo a soja como principal matéria-prima, compete com a produção de alimentos, podendo aumentar seus preços; isso pode ocorrer pela menor oferta desses alimentos ou pelo aumento do valor das terras e da logística de transporte. Nesse sentido, um aumento na mistura do biodiesel ao diesel precisa ser muito bem estruturado, pois além de causar um acréscimo no custo dos alimentos, da cesta básica e dos fretes, causaria um aumento da inflação. 
Pauta de discussões políticas, a promoção do uso de carros a diesel e a liberação do óleo vegetal como combustível são elementos que se relacionam à dinâmica do mercado de energia. Elementos como desenvolvimento tecnológico dos veículos, níveis de emissões, novas tecnologias de produção de biocombustíveis e redução de preços seguramente farão parte das discussões acima referidas.

Com a grande oferta industrial existente no setor, o Governo está sendo pressionado a aprovar novos incrementos nos percentuais de mistura. Por outro lado, para que sejam mantidas as metas definidas pelo PNPB, o crescimento no uso do biodiesel deverá contemplar mudanças estratégicas.

Segundo Mendes e Costa (2010), a melhor maneira para aumentar a competitividade do biodiesel de maneira sustentável é desenvolver novas matérias-primas, de preferência não alimentícias, diminuir o preço para o consumidor final, com aumento da produtividade, aumentar a inclusão social e exportar parte da produção. Do contrário, não haverá como sustentar grandes aumentos da demanda, causados pelo aumento do percentual obrigatório de mistura no diesel.

Dessa maneira, pode-se concluir que o contínuo crescimento e desenvolvimento do setor dependem de novas definições por parte do Governo, de maneira a preencher as lacunas não alcançadas pelo PNPB, principalmente no que diz respeito às questões sociais de inclusão, distribuição de renda, promoção de igualdade regional e incentivo à agricultura familiar, além de maiores investimentos em pesquisa e desenvolvimento.

\section{REFERÊNCIAS}

ABIOVE - Associação Brasileira das Indústrias de Óleos Vegetais. Disponível em: <http:// www.abiove.com.br>. Acesso em: 11/12/2010.

ABRAMOVAY, R.; MAGALHÃES, R. S. O acesso dos agricultores familiares aos mercados de biodiesel: parcerias entre grandes empresas e movimentos sociais, 2007. Disponível em: <http://www.usp.br/feaecon/media/fck/File/Biodiesel_AIEA2_Portugues.pdf >. Acesso em: $14 / 3 / 2011$.

ANP - Agência Nacional do Petróleo, Gás Natural e Biocombustíveis. Disponível em: <http:/ / www.anp.gov.br>. Acesso em: 11/12/2010.

ANP - Agência Nacional do Petróleo, Gás Natural e Biocombustíveis. Anuário estatístico brasileiro do petróleo, gás natural e biocombustíveis - 2010. 227 p. Disponível em: <http:// www.anp.gov.br>. Acesso em: 5/3/2011.

ANP - Agência Nacional do Petróleo, Gás Natural e Biocombustíveis. Produção de biodiesel - metros cúbicos. Disponível em: <http://www.anp.gov.br/ ?id=472>. Acesso em: 23/3/ 2011.

BOLETIM MENSAL DE BIODIESEL. ANP, Superintendência de refino e processamento de 
gás natural (SRP), 2010. Disponível em: <http://www.anp.gov.br>. Acesso em: 11/12/2010.

CÂMARA, G. M. S. Biodiesel Brasil - estado atual da arte. 2006. 26 p. Disponível em: < http:/ / www.cib.org.br/pdf/biodiesel_brasil.pdf>. Acesso em: 18/2/2011.

CARVALHO, R. L. de; POTENGY, G. F.; KATO, K. PNPB e sistemas produtivos da agricultura familiar no semiárido: oportunidades e limites. 2007. 16 p. Disponível em: <http:// www.cnpat.embrapa.br/sbsp/anais/Trab_Format_PDF/197.pdf>. Acesso em: 19/2/2011.

HEIFFIG, L. S.; CÂMARA, G. M. S. Potencial da cultura do pinhão-manso como fonte de matéria-prima para o Programa Nacional de Produção e Uso do Biodiesel. In: CÂMARA, G. M. S.; HEIFFIG, L. S. (Coord.). Agronegócio de plantas oleaginosas: matérias-primas para biodiesel. Piracicaba: ESALQ, 2006.

KNOTHE, G.; GERPEN, J. V.; KRAHL, J.; RAMOS, L. P. Manual de biodiesel. 1ª reimpressão. São Paulo: Edgard Blücher, 2006.

MENDES, A. P. do A.; COSTA, R. C. da. Mercado brasileiro de biodiesel e perspectivas futuras. BNDES Setorial 31, p. 253-280. Disponível em: <http://www.bndes.gov.br/SiteBNDES/bndes/bndes_pt/Institucional/Publicacoes/Consulta_Expressa/Setor/Biocombustiveis/201003_07.html>. Acesso em: 2/2/2011.

PARENTE, E. J. S. Biodiesel: uma aventura tecnológica num país engraçado. Fortaleza: Unigráfica, 2003.

PNPB - Portal do Programa Nacional de Produção e Uso de Biodiesel. Disponível em: < http:/ / www.biodiesel.gov.br>. Acesso: 11/3/2011.

RAMOS, L. P. Conversão de óleos vegetais em biocombustível alternativo ao diesel convencional. In: CONGRESSO BRASILEIRO DE SOJA, 1999, Londrina. Anais... Londrina: Embrapa, 1999, p. 233-236.

RAMOS, L. P.; DOMINGOS, A. K.; KUCEK, K. T.; WILHELM, H. M. Biodiesel: um projeto de sustentabilidade econômica e socioambiental para o Brasil. Biotecnologia: Ciência e Desenvolvimento, v. 31, p. 28-37, 2003.

REVISTA BIODIESELBR, ano 3, n. 18, ago./set. 2010.

REVISTA BIODIESELBR, ano 4, n. 20, dez. 2010/jan. 2011.

SAAD, E. B.; DOMINGOS, A. K.; CÉSAR-OLIVEIRA, M. A. F.; WILHELM, H. M.; RAMOS, L. P. Variação da qualidade do biodiesel em função da matéria-prima de origem vegetal. In: CÂMARA, G. M. S.; HEIFFIG, L. S. (Coord.). Agronegócio de plantas oleaginosas: matérias-primas para biodiesel. Piracicaba: ESALQ, 2006. 
